humano como los cereales y las oleaginosas. Esta estrategia de mejoramiento permite la incorporación de un rasgo deseado sobre un fondo genético seleccionado y la incorporación de genes de los más diversos orígenes (hongos, bacterias, animales y otros vegetales) que, debidamente adaptados para su expresión en plantas, aportan características con una muy baja probabilidad de que sean incorporadas en forma espontánea en el genotipo de interés. A través de esta técnica es posible el logro de plantas con nuevos diseños y colores o expresando resistencia a enfermedades (bacterianas, fúngicas y virósicas), insectos y herbicidas, así como la adaptación a ciertos estreses.

Agrobacterium rhizogenes y el gen rol $C$ de su plásmido $\mathrm{Ri}$ es una poderosísima y relativamente económica herramienta para aplicar en el mejoramiento de ornamentales. En efecto, la introducción de este gen en el genoma de algunas especies ornamentales ha permitido la obtención de plantas de menor tamaño, flores de menor diámetro y pétalos y hojas modificados, lo que implica una significativa modificación de la arquitectura de la planta. En clavel, por ejemplo, la incorporación de este transgén produjo una serie de modificaciones morfológicas muy ventajosas como ser disminución de la dominancia apical, mayor capacidad de enraizamiento, mejor incorporación de metabolitos y mayor producción de varas (se incrementó tres veces en relación al producto no transgénico). En términos prácticos, estas modificaciones implican una sensible mejora en el rendimiento del cul- tivo. Los marcadores moleculares como herramienta para la caracterización y diferenciación entre genotipos fueron rápidamente utilizados por genetistas y mejoradores de plantas. Su neutralidad con relación al proceso de selección, su poder de resolución, la celeridad con que se obtiene la información y la independencia de los estados fisiológicos del material en estudio y de la época del año, son algunas de las ventajas que ofrece esta herramienta. Esta técnica permite, a través del conocimiento de la diversidad genética de la que se dispone, diseñar nuevas estrategias para el mejoramiento esto es, preseleccionando individuos según su distancias genéticas para cruzamientos dirigidos. Asimismo, detectando las bandas asociadas a determinadas características es posible realizar una selección asistida por marcadores y de esa forma acortar los tiempos de selección. Otra aplicación de los marcadores moleculares es el desarrollo de las denominadas huellas digitales genéticas con las cuales se podrán efectuar diagnósticos de gran certeza en la identificación varietal ya sea las defensas de los derechos de obtentor, así como de los intereses de los productores. En suma, la aplicación de herramientas biotecnológicas en el mejoramiento y la producción de cultivos ornamentales estimulan el desarrollo de una industria que se caracteriza por su alto impacto social. En esta presentación se hará un resumen del estado del arte de la biotecnología aplicada a cultivos ornamentales y se efectuará una reseña de los trabajos efectuados en el área en el Instituto de Floricultura.

\title{
INNOVACIÓN EN FLORICULTURA EN CHILE: ANÁLISIS Y SITUACIÓN ACTUAL
}

\section{FLORICULTURAL INNOVATION IN CHILE: ANALYSIS AND PRESENT SITUATION}

\section{Samarotto, M. \\ Coordinadora Programa Flores FIA. Loreley 1582, La Reina Santiago, Chile. \\ E-mail: msamarot@fia.gob.cl}

La floricultura nacional, desde sus inicios, se caracterizó por desarrollarse fundamentalmente en la zona central del país, entre la IV y la
Región Metropolitana, siendo la mayor región productora la $\mathrm{V}$, con la mayor superficie explotada en el país (cerca del 56\%), seguida por la Región 
Metropolitana y la IV Región, de acuerdo a cifras oficiales del sexto censo agropecuario (1997).

Desde hace algunos años este escenario ha experimentado ciertas transformaciones que han permitido diversificar la oferta nacional en flores, al incorporar un mayor número de especies tanto nativas como introducidas, y han dado la posibilidad de involucrar a nuevas regiones a la floricultura nacional. En la última década se han incorporado diferentes zonas de producción, encontrándose hoy cultivos desde la I a la XII Región. Con relación a las especies involucradas, la mayor cantidad de especies contempladas en iniciativas productivas, han sido lilium, peonía, tulipán, calas, proteas y especies nativas, siendo más de 15 las especies evaluadas como nuevas alternativas de cultivo. A la vez, la floricultura no sólo se ha enfocado al negocio de la producción de flores de corte, sino ampliado a producción de bulbos, follajes, semillas y plantas en maceta.

Estos cambios han sido el resultado de un esfuerzo conjunto, en que se han sumado la iniciativa de los sectores productivos y de investigación, y el apoyo del sector público, a través de fondos concursables como los de FIA, FONTEC, FONDEF, SAG, FDI y FNDR que hacen que las perspectivas de crecimiento y desarrollo de la floricultura sean reales.

En este marco, se han ejecutado entre los años 1996 y 2004 un conjunto de aproximadamente 70 proyectos de innovación con el aporte de estos fondos. Estos proyectos corresponden en su mayoría a iniciativas de privados, como parte de una constante búsqueda a nuevas alternativas productivas. Las universidades también han tenido un rol activo en materia de investigación especialmente en el área de la flora nativa. Del total de proyectos, un $63 \%$ han sido ejecutados por privados, un $29 \%$ por universidades y un $8 \%$ por organismos públicos.

La base de estos proyectos ha sido introducir y/o adaptar nuevas especies, como lo indica el hecho de que el $31 \%$ de los proyectos financiados corresponden a esta línea temática, seguido por iniciativas en nuevas técnicas de producción y propagación ( $24 \%$ y $7 \%$ respectivamente). Un especial énfasis se ha dado a las especies nativas en términos de multiplicación y manejo y se han abordado en menor medida los temas de in- novación en comercialización, sustentabilidad, producción limpia y calidad.

En cuanto a las especies consideradas, los proyectos han estudiado principalmente las especies lilium y peonías, incluidas en siete iniciativas; tulipán y especies nativas en seis; clavel en cuatro, lisianthus y callas en tres, gladiolo y protea en dos, y liatris, orchideas, rosas, sandersonias, iris, jacintos, pensamientos y crisantemos en una. Por otra parte, existen nueve iniciativas que consideran especies distintas a las tradicionales de corte y producción de bulbos, las cuales están enfocadas al estudio y evaluación de distintas especies con alguna posibilidad productiva como el caso de semillas y el rescate de la flora nativa.

A la vez, la innovación de la floricultura en Chile ha estado respaldada por la participación de numerosos productores, asesores e investigadores en diversas giras de captura tecnológicas a los principales referentes de la producción mundial de flores como Holanda, Nueva Zelanda y Colombia. A la vez, la realización en el país de numerosos seminarios de actualización técnico comercial, con la participación de expertos extranjeros y nacionales, han permitido contar con información variada y necesaria para sentar las bases de un desarrollo tecnológico confiable. En los últimos años, también ha existido un fuerte apoyo en la formación de profesionales y productores en aspectos de producción, gestión y comercialización, a través de cursos de especialización, pasantías, becas de especialización que han permitido ampliar y fortalecer las competencias necesarias para enfrentar un exigente negocio.

Como resultado de esta evolución, se ha observado un incremento de las exportaciones del rubro, que en el año 2004 llegaron a US\$ 3,58 millones valor FOB en flores de corte, que superó en un $19 \%$ al registrado en el 2003 , de acuerdo con cifras de ODEPA. Datos más recientes de la misma fuente, indican que entre enero y abril del año 2005, existió un aumento de un $46,4 \%$ en los envíos de flores respecto al mismo período del año 2004. En términos de volumen, mientras el año 2003 se exportaron 451.557 kilos, durante el año 2004 la cantidad de flores exportadas creció a 566.825 kilos. En cuanto al aumento del valor en los últimos años, 
es importante destacar que, más que deberse a una expansión en términos de volumen, es resultado del hecho de que actualmente se están enviando al exterior especies con mayor valor comercial. En términos proporcionales, hoy se envían menos claveles y más especies como lilium, peonías y proteas que se comercializan a un mayor valor unitario. Por otro lado, de acuerdo a Prochile durante el 2004 se exportó un volumen total de 76,2 millones de bulbos por un monto de US\$ 13,7 millones, con un incremento de un $31,3 \%$ en el volumen exportado y un incremento de un $30,3 \%$ en el monto exportado el año 2004, correspondiendo principalmente a las especies de lilium y tulipán.

En cuanto a destinos de estas exportaciones cabe señalar que nuestro principal mercado es Estados
Unidos, que recibió el año 2004 , el $81,5 \%$ del total de flores exportado por Chile, seguido de Holanda con 17,1\%. También es necesario indicar que existe actualmente una mayor diversificación en cuanto al número de países de destino de nuestras exportaciones, destacando Reino Unido, Emiratos Árabes, Colombia y Portugal.

En este escenario, se deben considerar además las importaciones de flores de corte, especialmente durante los meses invernales, Chile compró US\$ 1,9 millones (CIF) en 2004, registrándose un aumento de $44,3 \%$ con relación al año 2003. La principal especie demandada es la rosa ecuatoriana, en la cual se incrementaron sus envíos en un $38,9 \%$ comparando los años 2003 al 2004, alcanzando los US\$ 1,35 millones (CIF) este último año.

Agro Sur 34 (1-2): 5-7 2006

\title{
BIOTECNOLOGÍA Y MEJORAMIENTO DE ESPECIES CHILENAS DEL GÉNERO Rhodophiala Presl. (Amaryllidaceae)
}

\section{BIOTECHNOLOGY AND PLANT BREEDING OF TWO CHILEAN SPECIES OF Rhodophiala Presl. (Amaryllidaceae)}

\author{
Seemann', P.; Riegel', R.; Jara, G'., Muñoz', M.; Schiappacasse'2, E; Peñailillo² P. y Basoalto ${ }^{2}$, A. \\ 'Universidad Austral de Chile, Facultad de Ciencias Agrarias. \\ ${ }^{2}$ Universidad de Talca, Facultad de Ciencias Agrarias \\ pseemann@uach.cl
}

\section{INTRODUCCIÓN}

En Chile las especies nativas, en general, han sido poco valoradas y aún menos estudiadas en relación a su uso potencial como plantas ornamentales. Es un hecho que el país posee una enorme diversidad de especies bulbosas endémicas, constituyendo un pool genético que merece ser estudiado y analizado con el objetivo de crear y mejorar nuevas variedades. En floricultura se busca que las plantas cultivadas tengan grandes flores y fuertes tallos. Para esto, el uso de material poliploide ha producido grandes avances en el mejoramiento de especies florícolas. Si bien la poliploidía es una condición genética frecuente en las angiospermas, también puede ser inducida artificialmente mediante la aplicación de antimitóticos como la colchicina. La duplicación cromosómica que genera la in- ducción de autopoliploidía provoca gigantismo celular y mayor duración de los ciclos, con lo cual es posible obtener órganos más grandes. Es por esta razón que los individuos poliploides suelen presentar flores de mayor tamaño, mayor intensidad de la pigmentación y mayor duración de la floración, los cuales pueden ser inducidos por medios artificiales. Entre los géneros con potencial de mejoramiento genético, hay varias especies de Rhodophiala que presentan características que las hacen atractivas como flores de corte, plantas de maceta o de jardín, sin embargo, el mejorar sus características naturales las haría más atractivas para diferentes mercados. Es por ello que dentro del marco del Proyecto FIA-BIOT-01-A-071 "Aplicaciones biotecnológicas en el mejoramiento de especies de Rhodophiala chilenas" se ha iniciado el estudio de las especies Rhodophiala rhodolirion, R. splendens, 